\title{
The effect of daily probiotics on the incidence and severity of necrotizing enterocolitis in infants with very low birth weight
}

\author{
Jessica Que, BSc \\ Rhonda Van Oerle, BSc, RD, CNSC \\ Susan Albersheim, MD, PhD \\ Julia Panczuk, MD, MPH \\ Hannah Piper, MD
}

Accepted January 11, 2021

\section{Correspondence to: \\ H. Piper \\ 4480 Oak St \\ ACB K0 134 \\ Vancouver BC V6H 3V4 \\ hannah.piper@cw.bc.ca}

Cite as: Can J Surg 2021 December 1; 64(6). doi: 10.1503/cjs.016920

\begin{abstract}
Background: Necrotizing enterocolitis remains a leading cause of morbidity and mortality in premature infants. The role of prophylactic probiotics in its prevention is unclear. This study evaluates the effect of routine probiotics on the incidence and severity of necrotizing enterocolitis in infants with very low birth weight in the neonatal intensive care unit.
\end{abstract}

Methods: This retrospective cohort study compared infants cared for at a single institution before and after implementation of routine probiotic administration (2014- 2018). Babies born after July 2016 received probiotics containing Bifidobacterium and Lactobacillus daily until 35 weeks corrected gestational age. Baseline characteristics, necrotizing enterocolitis incidence and severity, infections, mortality, and length of stay were compared between groups.

Results: Of the 665 infants included in the study, 310 received probiotics and 355 did not. The 2 groups did not differ with regard to gestational age, birth anthropometrics, mode of delivery, comorbidities, and type of enteral feed. The incidence of necrotizing enterocolitis (Bell's stage 2 of 3 ) was similar between groups (4\% v. $5 \%$, $p=0.35)$, as was its severity $(p=0.10)$. In addition, there were no significant differences in mortality and length of stay between the groups. Significantly fewer infants receiving probiotics developed infections $(27 \%$ v. $34 \%, p=0.046)$, with the rate of urinary tract infections having the largest reduction.

Conclusion: The routine use of Bifidobacterium and Lactobacillus probiotics in infants with very low birth weight did not significantly affect the incidence and severity of necrotizing enterocolitis. However, the use of probiotics was associated with fewer overall infections.

Contexte : L'entérocolite nécrosante demeure une importante cause de morbidité et de mortalité chez les nourrissons prématurés. Le rôle des probiotiques prophylactiques pour la prévention de l'entérocolite nécrosante reste à déterminer. Cette étude évalue l'effet de l'administration systématique de probiotiques sur l'incidence et la gravité de l'entérocolite nécrosante chez les nourrissons de très faible poids à la naissance dans les unités de soins intensifs néonataux.

Méthodes : Cette étude de cohorte rétrospective a comparé les nourrissons soignés dans un seul établissement avant et après la mise en place d'un protocole d'administration systématique de probiotiques (2014- 2018). Les bébés nés après juillet 2016 ont reçu des probiotiques à base de Bifidobacterium et de Lactobacilles jusqu'à un âge gestationnel corrigé de 35 semaines. Les caractéristiques de départ, l'incidence et la gravité de l'entérocolite nécrosante, les infections, la mortalité et la durée de l'hospitalisation ont été comparées entre les groupes.

Résultats : Parmi les 665 nourrissons inclus dans l'étude, 310 ont reçu des probiotiques, contre 355 qui n'en ont pas reçus. Les 2 groupes étaient semblables aux plans de l'âge gestationnel, des paramètres anthropométriques, du type d'accouchement, des comorbidités et du mode d'alimentation entérale. L'incidence de l'entérocolite nécrosante (stade de Bell 2 sur 3) était semblable entre les groupes ( $4 \%$ c. $5 \%, p=0,35$ ), tout comme la gravité $(p=0,10)$. De plus, on n'a noté aucune différence significative aux plans de la mortalité et de la durée de l'hospitalisation entre les groupes. Un nombre significativement moindre de nourrissons traités par probiotiques ont présenté des infections ( $27 \% \mathrm{c}$. $34 \%, p=0,046)$; la réduction la plus marquée concernant les infections urinaires.

Conclusion : L'utilisation systématique de probiotiques à base de Bifidobacterium et de Lactobacilles chez les nourrissons de très faible poids à la naissance n'a pas significativement modifié l'incidence ni la gravité de l'entérocolite nécrosante. Par contre, elle a été associée à une baisse globale du nombre d'infections. 
$\mathbf{N}$ ecrotizing enterocolitis remains a leading cause of morbidity and mortality in premature infants, particularly those with very low birth weight $(<1500 \mathrm{~g}) .^{1-3}$ Despite efforts to prevent necrotizing enterocolitis, including standardizing feeding protocols and increased use of breast milk, the incidence of necrotizing enterocolitis has not decreased significantly. ${ }^{4}$ In North America, approximately $7 \%$ of neonates with very low birth weight develop necrotizing enterocolitis, and $15 \%-30 \%$ of them do not survive. ${ }^{5}$ In those who do survive, necrotizing enterocolitis is associated with long-term complications, such as growth delay and neurodevelopment impairment. ${ }^{6,7}$

While the pathogenesis of necrotizing enterocolitis is not completely understood, gut immaturity and microbial dysbiosis appear to be contributing risk factors in its development. ${ }^{8}$ The premature gut is susceptible owing to immature tight junctions, decreased mucus-producing goblet cells, and increased expression of Toll-like receptor $4 .{ }^{9}$ These factors may allow bacteria to more easily translocate across gut mucosa and cause a dysregulated inflammatory response. Further, the gut microbiome of premature infants has limited diversity and reduced abundance of beneficial bacteria including Bifidobacterium, which is usually a significant component of the microbiome in healthy breastfed term infants. ${ }^{10}$ The use of probiotics to populate the neonatal gut has been recommended as a strategy to prevent necrotizing enterocolitis. ${ }^{11-15}$ Despite the evidence, probiotic administration has not been widely implemented in neonatal intensive care units (NICUs) in North America. ${ }^{16}$ The exact strains, dosing, and timing of probiotic administration remain controversial. Although probiotics are generally considered to be safe in this population, there are rare cases of probiotic contamination with pathogens and probiotic-associated sepsis. ${ }^{17-19}$

In July 2016, routine probiotic supplementation was introduced as part of the standard of care for infants with very low birth weight in the NICU at British Columbia Women's Hospital (BCWH) in order to reduce the incidence of necrotizing enterocolitis. The purpose of this study was to evaluate the effect of daily probiotics on the incidence and severity of necrotizing enterocolitis in those infants.

\section{Methods}

After study approval was obtained from the British Columbia Women and Children's Research Ethics Board (H19-00515), we reviewed the records of infants with very low birth weight who received care in the $\mathrm{BCWH}$ NICU between 2014 and 2018. The routine use of probiotics for all infants with very low birth weight was introduced in July 2016; therefore, we compared infants born before that time with those born after. Infants born in the month of July 2016 were excluded, as this was when probiotics were being introduced and their use was not yet routine. Infants transferred to the NICU from an outside hospital after the age of 3 weeks were also excluded as probiotic duration was reduced. There was a modest increase in the rate of feed advancement by $5-15 \mathrm{~mL} / \mathrm{kg} / \mathrm{d}$ to a maximum of $30 \mathrm{~mL} / \mathrm{kg} / \mathrm{d}$ in September 2016. Apart from this change to the feeding protocol, there were no additional significant changes to neonatal management.

After July 2016, all infants with very low birth weight except those with known gastrointestinal pathology or obstruction received $0.5 \mathrm{~g}$ of probiotics mixed with $1 \mathrm{~mL}$ of sterile water daily from the time of initiation of feeds until the infant reached 35 weeks gestational age. Probiotics were discontinued for any infant who developed necrotizing enterocolitis. The administered probiotic was composed of 4 Bifidobacterium species and 1 Lactobacillus species: B. breve, $B$. bifidum, B. infantis, B. longum, and L. rbamnosus $\left(2 \times 10^{9}\right.$ colony forming units [CFU] total). This probiotic is a licensed natural health product and meets the quality assurance requirements of Canada's Natural Health Product Regulations. Donor breast milk was provided when the mother's own milk was not available, and human milk fortifier was used to supplement feeds when needed. Prebiotics, which are nondigestible compounds that promote the growth of gut microbiota, were not used during the study period.

We reviewed the records of eligible babies for demographic information, neonatal course, and outcomes. Our primary outcome was the incidence of necrotizing enterocolitis, defined as modified Bell's stage 2 or $3 .^{20}$ Necrotizing enterocolitis stages were assigned based on a review of clinical charts, operative reports and abdominal radiographs formally read by pediatric radiologists.

Secondary outcomes included the severity of necrotizing enterocolitis, overall mortality, infection rates, and length of hospital stay. An infection was defined as any positive culture during the infant's stay in the NICU, and length of hospital stay was defined as the number of days in the NICU, as almost all babies were discharged home from the NICU.

\section{Statistical analysis}

Statistical analysis was conducted using $\mathrm{R}$ version 3.6.1. Baseline characteristics were described using proportions (categorical variables) and medians (ordinal and continuous variables). We used the $\chi^{2}$, Welch $t$, and MannWhitney $U$ tests to perform univariate analysis of categorical, numerical, and ordinal outcomes, respectively.

\section{Results}

Between 2014 and 2018, 810 infants with very low birth weight received care in the BCWH NICU. Of the 665 infants who met the inclusion criteria, 310 received probiotics and 355 did not. Baseline characteristics were similar between the probiotic and no-probiotic groups. The groups did not differ significantly with regard to gestational age at birth, birth anthropometrics, delivery hospital, mode 
Table 1. Baseline characteristics of infants with very low birth weight who received or did not receive probiotics to prevent necrotizing enterocolitis

\begin{tabular}{|c|c|c|c|}
\hline \multirow[b]{2}{*}{ Characteristic } & \multicolumn{2}{|c|}{ Group; median [IQR] or no. (\%) } & \multirow[b]{2}{*}{$p$ value } \\
\hline & $\begin{array}{c}\text { No probiotics } \\
\quad(n=355)\end{array}$ & $\begin{array}{l}\text { Probiotics } \\
(n=310)\end{array}$ & \\
\hline Gestational age, wk & $28.4[22.4-30.4]$ & $28.6[26.6-30.1]$ & 0.70 \\
\hline Birth weight, $g$ & 1090 [830-1300] & 1060 [800-1293] & 0.24 \\
\hline Apgar 1min & $5[3-7]$ & $5[2-6]$ & 0.03 \\
\hline Apgar 5min & $7[6-8]$ & 7 [5.5-8] & 0.02 \\
\hline Female sex & $146(41)$ & $143(46)$ & 0.18 \\
\hline Inborn & $287(81)$ & $252(82)$ & 0.87 \\
\hline Breastmilk & $272(88)$ & $270(92)$ & 0.16 \\
\hline Milk fortification & $254(84)$ & $241(81)$ & 0.38 \\
\hline Cesarean section & $257(72)$ & $230(74)$ & 0.55 \\
\hline Maternal infection & $85(24)$ & $38(12)$ & $<0.001$ \\
\hline $\begin{array}{l}\text { Antenatal } \\
\text { corticosteroid }\end{array}$ & $293(83)$ & $253(83)$ & 0.79 \\
\hline Multiple gestation & $136(39)$ & $87(28)$ & 0.005 \\
\hline Any comorbidity & $308(96)$ & $297(97)$ & 0.60 \\
\hline $\begin{array}{l}\text { Respiratory } \\
\text { comorbidity }\end{array}$ & $300(93)$ & $287(93)$ & 0.99 \\
\hline Cardiac comorbidity & $150(47)$ & $152(50)$ & 0.49 \\
\hline $\begin{array}{l}\text { Umbilical venous } \\
\text { catheter }\end{array}$ & $268(78)$ & $224(72)$ & 0.12 \\
\hline $\begin{array}{l}\text { Central venous } \\
\text { catheter }\end{array}$ & $210(62)$ & $193(63)$ & 0.85 \\
\hline $\mathrm{IQR}=$ & & & \\
\hline
\end{tabular}

of delivery, type of enteral feed, or feed fortification. The presence of respiratory and cardiac comorbidities was also similar between the groups, with the most common being respiratory distress syndrome and patent ductus arteriosus. There was no difference in the number of patients in each group with umbilical venous or central venous catheters; however, there were more maternal infections, multiple gestations, and higher Apgar scores observed in the noprobiotic group (Table 1).

A total of 31 infants with very low birth weight developed severe necrotizing enterocolitis during the study period. Their median gestational age was 25.6 weeks and median birth weight was $800 \mathrm{~g}$. There was no significant difference in the incidence of necrotizing enterocolitis between infants who received probiotics and those who did not $(5 \%$ v. $4 \%, p=0.35)$. In addition, probiotics had no significant effect on the severity of necrotizing enterocolitis $(p=0.10)$. Infants receiving probiotics had a similar mortality rate and length of stay in the NICU as those who did not receive probiotics (Table 2).

Infants who received probiotics had fewer overall infections than those who $\operatorname{did} \operatorname{not}(27 \%$ v. $34 \%, p=0.046)$, with the rate of urinary tract infections (UTIs) having the largest reduction (17\% v. $45 \%)$. Bloodstream and respiratory tract infections were the most common overall. None of the infants had a bloodstream infection from Bifidobacterium or Lactobacillus.

\begin{tabular}{|c|c|c|c|}
\hline \multirow[b]{2}{*}{ Characteristic } & \multicolumn{2}{|c|}{ Group; median [IQR] or no. (\%) } & \multirow[b]{2}{*}{$p$ value } \\
\hline & $\begin{array}{c}\text { No probiotics } \\
(n=355)\end{array}$ & $\begin{array}{l}\text { Probiotics } \\
(n=310)\end{array}$ & \\
\hline Severe NEC & $14(4)$ & $17(5)$ & 0.35 \\
\hline $\begin{array}{l}\text { NEC by modified Bell } \\
\text { stage }\end{array}$ & & & 0.10 \\
\hline NEC stage IA or IB & 70 (83) & $58(77)$ & \\
\hline NEC stage IIA or IIB & $2(2)$ & $7(9)$ & \\
\hline NEC stage IIIA or IIIB & $12(14)$ & $10(13)$ & \\
\hline Mortality & $25(7)$ & $33(11)$ & 0.10 \\
\hline Any infection & $111(34)$ & $83(27)$ & 0.046 \\
\hline Blood stream infection & $59(18)$ & $43(14)$ & 0.15 \\
\hline Respiratory infection & $36(11)$ & $31(10)$ & 0.67 \\
\hline Urinary tract infection & $50(16)$ & $14(5)$ & $<0.001$ \\
\hline Length of stay, $d$ & 58 [20-98] & $52.5[22-92.25]$ & 0.42 \\
\hline
\end{tabular}

\section{Discussion}

In this study, we found that the implementation of routine probiotic supplementation did not significantly impact the incidence of necrotizing enterocolitis, its severity, or mortality rates in infants with very low birth weight. However, we found that babies receiving probiotics had fewer overall infections than those who did not receive probiotics.

These findings conflict somewhat with the most recent Cochrane review, conducted in 2014, which found that probiotics decreased the incidence of necrotizing enterocolitis but did not affect rates of culture-positive sepsis. ${ }^{11}$ While many randomized controlled trials (RCTs) support the use of prophylactic probiotics, several others did not find significant benefit. ${ }^{21-24}$ The largest RCT conducted to date, including 1310 very preterm infants, found a similar incidence of necrotizing enterocolitis in infants who received the probiotic $B$. breve and those who received placebo ( $9 \%$ v. $10 \%){ }^{23}$ This RCT shows that probiotics may not be universally effective and that the results may vary depending on the type of probiotic, duration of treatment and the treatment setting. Several recent RCTs examining Bifidobacterium or Lactobacillus also found that probiotics did not significantly reduce the incidence of necrotizing enterocolitis. ${ }^{24-26}$ Another retrospective cohort study using a probiotic mixture (Streptococcus thermophilus, B. infantis, and B. bifidum) found that the incidence of necrotizing enterocolitis was similar before and after the implementation of a probiotic administration protocol $(2.8 \%$ v. $2.4 \%) .{ }^{27}$ These findings could be attributed to the lower gestational age of the probiotic group and a low incidence of necrotizing enterocolitis at the studied NICU. Further, Kane and colleagues $^{28}$ found that the introduction of probiotics was associated with an increase in the incidence of necrotizing 
enterocolitis from $10.2 \%$ to $16.8 \%$ (odds ratio [OR] 2.1, $95 \%$ confidence interval $[\mathrm{CI}] 1.25-3.54, p=0.005)$. The probiotic administered was L. rhamnosus GG (LGG), the most commonly used probiotic in American NICUs according to a survey by Viswanathan and colleagues. ${ }^{29}$

In contrast, 3 of the 5 retrospective studies conducted in North America found significant reductions in the incidence of necrotizing enterocolitis after routine probiotic administration. ${ }^{16,30}$ Singh and colleagues ${ }^{16}$ evaluated probiotic use in a nationwide study of 3286 infants with a gestational age below 29 weeks admitted to 30 participating tertiary NICUs in Canada, including the BCWH NICU. ${ }^{16}$ Fifty-five percent of participating NICUs implemented a probiotic protocol during their study period (January 2014 to December 2015), with $80 \%$ using probiotics containing Bifidobacterium and Lactobacillus species and 20\% using another product containing L. reuteri. Despite a nonsignificant decrease in the incidence of necrotizing enterocolitis with univariate analysis $(7.80 \%$ to $7.67 \%, p=0.91)$, they found that probiotics were associated with a reduced risk of necrotizing enterocolitis using logistic regression models (OR 0.64, 95\% CI 0.41-0.996). Although the study had the advantage of a large sample size, only $21 \%$ of the included infants received probiotics, and the study period preceded the introduction of probiotics at BCWH NICU. Retrospective studies by Janvier and colleagues ${ }^{30}$ and Sekhon and colleagues ${ }^{31}$ also found that probiotics containing Bifidobacterium and Lactobacillus were associated with a reduced risk of necrotizing enterocolitis from $9.8 \%$ to $5.4 \%$ (OR $0.51,95 \%$ CI $0.26-0.98)^{30}$ and $7 \%$ to $2 \%^{31}$ $(p<0.001)$, respectively. However, in the study by Sekhon and colleagues, ${ }^{31}$ changes in practice, including the introduction of a feeding protocol 9 months after the probiotic protocol, could have contributed to decreases in the incidence of necrotizing enterocolitis. Other than the introduction of probiotics, we had minimal changes during the study period to the overall management of infants with very low birth weight. There was an increase in the rate of feed advancement in September 2016, but faster feeds have not been directly associated with a change in the incidence of necrotizing enterocolitis according to the latest Cochrane review, published in 2017.32 A recent large retrospective study of neonatal units in New Zealand also found a significant decrease in late-onset sepsis and necrotizing enterocolitis from $2.6 \%$ to $1.8 \%$ (OR $0.62,95 \%$ CI 0.41-0.94) despite a low baseline incidence of necrotizing enterocolitis. ${ }^{33}$ Although breast milk was used more at onset of feeding in their probiotic group, multivariate logistic regression showed minimal effect by confounders. At the BCWH NICU, the use of maternal and donor breast milk did not change significantly before and after probiotic introduction ( $88 \%$ v. $92 \%, p=0.16$ ).

These mixed results emphasize the need to assess individual probiotic strains and products separately because some combinations may be more effective than others. The probiotic used in our study was chosen because of its availability in Canada, efficacy in other Canadian retrospective studies, and data from recent meta-analyses supporting similar probiotic mixtures. ${ }^{11,30,34}$ A 2019 systematic review of 34 studies and 9161 participants found that the incidence of necrotizing enterocolitis was significantly reduced after the administration of probiotic mixtures (OR $0.38,95 \% \mathrm{CI}$ $0.27-0.54) .{ }^{34}$ Multi-strain probiotics are thought to be more effective than single-strain probiotics because babies with necrotizing enterocolitis are often found to have reduced diversity in their fecal microbiome before a necrotizing enterocolitis episode. ${ }^{35}$ However, RCTs demonstrating efficacy of our study's probiotic mixture on the species level $(B$. breve, B. bifidum, B. infantis, B. longum, and L. rhamnosus) are lacking. A 2018 strain-specific network meta-analysis of 51 RCTs by the European Society for Pediatric Gastroenterology, Hepatology, and Nutrition Working Group for Probiotics showed that few studied strains had a statistically significant impact on the incidence of necrotizing enterocolitis and mortality. ${ }^{36}$ While both L. rhamnosus and B. lactis alone were effective in reducing the incidence of necrotizing enterocolitis, the combination of these 2 species showed no measurable effect.

Interestingly, we found a reduction in overall infections with probiotics use. While there was a nonsignificant decrease in bloodstream and respiratory infections, there was a substantial decrease in UTIs (Table 2). Premature infants are at a high risk of bloodstream infections and UTIs because of their immature immune system, intestinal permeability, and use of indwelling lines. ${ }^{37}$

Bacteremia in premature infants develops by translocation of gut flora into the bloodstream or introduction from the outside (e.g., from a peripherally inserted central catheter or central line), and UTIs can result from systemic or ascending infections. ${ }^{38,39}$ Forty percent of UTIs in the noprobiotic group had a concordant positive blood culture, which suggests some hematogenous spread of pathogens. Several studies found isogenicity between bloodstream pathogens and fecal isolates before infection, showing that the gut can be a reservoir for bloodstream-invading bacteria. ${ }^{40-42}$ Probiotics have been shown to have protective effects on the gut by decreasing intestinal permeability and producing bacteriocins, which help with outcompeting highly virulent and pathogenic bacteria. ${ }^{43-45} \mathrm{We}$ theorize that probiotics may reduce the rate of UTIs by decreasing the number of pathogenic gut bacteria that translocate from the gut or ascend from the lower urinary tract. However, an RCT by Dani and colleagues ${ }^{22}$ found that probiotics containing only L. rbamnosus did not reduce the rate of UTIs. Some RCTs found that probiotics reduced late-onset sepsis, but effects were nonsignificant in meta-analyses. ${ }^{11,46,47}$ The lower incidence of maternal infections in the probiotic group may have decreased the incidence of early-onset sepsis but likely did not affect the incidence of late-onset sepsis and rate of UTIs. 


\section{Limitations}

Our study has a number of limitations. As this was a retrospective study, we were unable to control for some confounding variables. Other unmeasured differences in maternal and infant characteristics could have contributed to the similar incidence of necrotizing enterocolitis before and after the introduction of probiotics; however, the 2 groups were similar in gestational age, birth weight and other comorbidities. The decrease in maternal infections, multiple gestation, and lower Apgar scores in the probiotic group were unlikely to have affected our results. Compared with other retrospective studies, there was a low overall incidence of necrotizing enterocolitis at the BCWH NICU (4.7\% v. 7\%-9.8\%). Hence, a larger sample size may be needed to show significant results. Despite these limitations, our study evaluates a practical and real-world implementation of routine probiotic supplementation. Probiotic use was part of the standard of care; therefore, there was limited selection bias and participant refusal. There was good protocol compliance with probiotic administration, increasing from 3\% to $84 \%$ after July 2016. Furthermore, probiotic use was shown to be safe, as there were no reported cases of probiotic-associated sepsis during the study period.

\section{Conclusion}

Routine probiotic supplementation of Lactobacillus and Bifidobacterium species did not significantly affect the incidence of necrotizing enterocolitis, mortality, or length of hospital stay at our centre. However, the overall rates of infections, including respiratory and bloodstream infections and UTIs, were lower in infants who received probiotics. Further study of the utility of routine use of probiotics in this population is warranted.

Affiliations: From the Faculty of Medicine, University of British Columbia, Vancouver, BC (Que); the BC Women's Hospital and Health Centre, Vancouver, BC (Van Oerle); the Department of Pediatrics, Faculty of Medicine, University of British Columbia/BC Children's Hospital, Vancouver, BC (Albersheim, Panczuk); and the Division of Pediatric Surgery, University of British Columbia/BC Children's Hospital, Vancouver, BC (Piper).

Competing interests: None declared.

Contributors: S. Albersheim, J. Panczuk and H. Piper designed the study. R. Van Oerle acquired the data, which J. Que analyzed. J. Que, S. Albersheim and H. Piper wrote the article, which all authors critically revised. All authors gave final approval of the article to be published.

Content licence: This is an Open Access article distributed in accordance with the terms of the Creative Commons Attribution (CC BYNC-ND 4.0) licence, which permits use, distribution and reproduction in any medium, provided that the original publication is properly cited, the use is noncommercial (i.e., research or educational use), and no modifications or adaptations are made. See: https://creativecommons.org/ licenses/by-nc-nd/4.0/

\section{References}

1. Berrington JE, Hearn RI, Bythell M, et al. Deaths in preterm infants: changing pathology over 2 decades. 7 Pediatr 2012;160:49-53.e1.

2. Simpson CDA, Ye XY, Hellmann J, et al. Trends in cause-specific mortality at a Canadian outborn NICU. Pediatrics 2010;126:e1538-44.

3. Fitzgibbons SC, Ching Y, Yu D, et al. Mortality of necrotizing enterocolitis expressed by birth weight categories. F Pediatr Surg 2009;44:1072-6.

4. Battersby C, Santhalingam T, Costeloe K, et al. Incidence of neonatal necrotising enterocolitis in high-income countries: a systematic review. Arch Dis Child Fetal Neonatal Ed 2018;103:F182-9.

5. Neu J, Walker WA. Necrotizing enterocolitis. N Engl f Med 2011; 364:255-64.

6. Hintz SR, Kendrick DE, Stoll BJ, et al. Neurodevelopmental and growth outcomes of extremely low birth weight infants after necrotizing enterocolitis. Pediatrics 2005;115:696-703.

7. Schulzke SM, Deshpande GC, Patole SK. Neurodevelopmental outcomes of very low-birth-weight infants with necrotizing enterocolitis: a systematic review of observational studies. Arch Pediatr Adolesc Med 2007;161:583-90.

8. Bazacliu C, Neu J. Pathophysiology of necrotizing enterocolitis: an update. Curr Pediatr Rev 2019;15:68-87.

9. Niño DF, Sodhi CP, Hackam DJ. Necrotizing enterocolitis: new insights into pathogenesis and mechanisms. Nat Rev Gastroenterol Hepatol 2016;13:590-600.

10. Underwood MA. Probiotics and the prevention of necrotizing enterocolitis. F Pediatr Surg 2019;54:405-12.

11. AlFaleh K, Anabrees J. Probiotics for prevention of necrotizing enterocolitis in preterm infants. Cochrane database Syst Rev 2014;4: CD005496.

12. Chowdhury T, Ali MM, Hossain MM, et al. Efficacy of probiotics versus placebo in the prevention of necrotizing enterocolitis in preterm very low birth weight infants: a double-blind randomized controlled trial. 7 Coll Physicians Surg Pak 2016;26:770-4.

13. Dilli D, Aydin B, Fettah ND, et al. The propre-save study: effects of probiotics and prebiotics alone or combined on necrotizing enterocolitis in very low birth weight infants. F Pediatr 2015;166:545-51.e1.

14. Guney-Varal I, Koksal N, Ozkan H, et al. The effect of early administration of combined multi-strain and multi-species probiotics on gastrointestinal morbidities and mortality in preterm infants: a randomized controlled trial in a tertiary care unit. Turk f Pediatr 2017;59:13-9.

15. Arora S, Khurana MS, Saini R. To study the role of probiotics in the prevention of necrotizing enterocolitis in preterm neonates. Int $\mathcal{f}$ Contemp Pediatr 2017;4:1792-1797.

16. Singh B, Shah PS, Afifi J, et al. Probiotics for preterm infants: a national retrospective cohort study. F Perinatol 2019;39:533-39.

17. Vallabhaneni S, Walker TA, Lockhart SR, et al. Fatal gastrointestinal mucormycosis in a premature infant associated with a contaminated dietary supplement - Connecticut, 2014. Morbidity and Mortality Weekly Report. 2015;64:155-6.

18. Esaiassen E, Cavanagh P, Hjerde E, et al. Bifidobacterium longum subspecies infantis bacteremia in 3 extremely preterm infants receiving probiotics. Emerg Infect Dis 2016;22:1664-6.

19. Dani C, Coviello C, Corsini I, et al. Lactobacillus sepsis and probiotic therapy in newborns: two new cases and literature review. A7P Rep 2016;6:e25-9.

20. Kliegman RM, Walsh MC. Neonatal necrotizing enterocolitis: Pathogenesis, classification, and spectrum of illness. Curr Probl Pediatr 1987;17:219-288.

21. Rojas MA, Lozano JM, Rojas MX, et al. Prophylactic probiotics to prevent death and nosocomial infection in preterm infants. Pediatrics 2012;130:e1113-20.

22. Dani C, Biadaioli R, Bertini G, et al. Probiotics feeding in prevention of urinary tract infection, bacterial sepsis and necrotizing enterocolitis in preterm infants. A prospective double-blind study. Biol Neonate 2002;82:103-8. 
23. Costeloe K, Hardy P, Juszczak E, et al. Bifidobacterium breve BBG001 in very preterm infants: a randomised controlled phase 3 trial. Lancet 2016;387:649-60.

24. Shashidhar A, Suman Rao PN, Nesargi S, et al. Probiotics for promoting feed tolerance in very low birth weight neonates - a randomized controlled trial. Indian Pediatr 2017;54:363-367.

25. Dongol Singh SS, Klobassa DS, Resch B, et al. Placebo controlled introduction of prophylactic supplementation of probiotics to decrease the incidence of necrotizing enterocolitis at Dhulikhel Hospital in Nepal. Kathmandu Univ Med f 2017;15:319-23.

26. Hays S, Jacquot A, Gauthier H, et al. Probiotics and growth in preterm infants: a randomized controlled trial, PREMAPRO study. Clin Nutr 2016;35:802-11.

27. Li D, Rosito G, Slagle T. Probiotics for the prevention of necrotizing enterocolitis in neonates: an 8-year retrospective cohort study. 7 Clin Pharm Ther 2013;38:445-9.

28. Kane AF, Bhatia AD, Denning PW, et al. Routine supplementation of Lactobacillus rhamnosus GG and risk of necrotizing enterocolitis in very low birth weight infants. 7 Pediatr 2018;195:73-79.e2

29. Viswanathan S, Lau C, Akbari H, et al. Survey and evidence based review of probiotics used in very low birth weight preterm infants within the United States. 7 Perinatol 201636:1106-1111.

30. Janvier A, Malo J, Barrington KJ. Cohort study of probiotics in a North American neonatal intensive care unit. 7 Pediatr 2014;164:980-5.

31. Sekhon MK, Grubb PH, Newman M, et al. Implementation of a probiotic protocol to reduce rates of necrotizing enterocolitis. 7 Perinatol 2019;39:1315-1322.

32. Oddie SJ, Young L, Mcguire W. Slow advancement of enteral feed volumes to prevent necrotising enterocolitis in very low birth weight infants. Cocbrane Database Syst Rev 2017;8:CD001241.

33. Meyer MP, Chow SSW, Alsweiler J, et al. Probiotics for prevention of severe necrotizing enterocolitis: experience of New Zealand neonatal intensive care units. Front Pediatr 2020;8:119.

34. Bi L, Yan B, Yang Q, et al. Which is the best probiotic treatment strategy to prevent the necrotizing enterocolitis in premature infants. Medicine (Baltimore). 2019;98:e17521.
35. Pammi M, Cope J, Tarr PI, et al. Intestinal dysbiosis in preterm infants preceding necrotizing enterocolitis: a systematic review and meta-analysis. Microbiome 2017;5:31.

36. Van Den Akker CHP, Van Goudoever JB, Szajewska H, et al. Probiotics for preterm infants: a strain-specific systematic review and network meta-analysis. F Pediatr Gastroenterol Nutr 2018;67:103-122.

37. Tarr PI, Warner BB. Gut bacteria and late-onset neonatal bloodstream infections in preterm infants. Semin Fetal Neonatal Med 2016;21:388-393.

38. Cho HJ, Cho HK. Central line-associated bloodstream infections in neonates. Korean 7 Pediatr 2019;62:79-84.

39. Cantey JB (editor). Neonatal infections: pathophysiology, diagnosis, and management. Springer; 2018.

40. Smith A, Saiman L, Zhou J, et al. Concordance of gastrointestinal tract colonization and subsequent bloodstream infections with gramnegative bacilli in very low birth weight infants in the neonatal intensive care unit. Pediatr Infect Dis f 2010;29:831-5.

41. Graham PL, Della-Latta P, Wu F, et al. The gastrointestinal tract serves as the reservoir for Gram-negative pathogens in very low birth weight infants. Pediatr Infect Dis f 2007;26:1153-6.

42. Carl MA, Ndao IM, Springman AC, et al. Sepsis from the gut: the enteric habitat of bacteria that cause late-onset neonatal bloodstream infections. Clin Infect Dis 2014;58:1211-8.

43. Spinler JK, Taweechotipatr M, Rognerud CL, et al. Human-derived probiotic Lactobacillus reuteri demonstrate antimicrobial activities targeting diverse enteric bacterial pathogens. Anaerobe 2008;14:166-71.

44. Guo S, Gillingham T, Guo Y, et al. Secretions of bifidobacterium infantis and lactobacillus acidophilus protect intestinal epithelial barrier function. 7 Pediatr Gastroenterol Nutr 2017;64:404-412.

45. Martinez FAC, Balciunas EM, Converti A, et al. Bacteriocin production by Bifidobacterium spp. A review. Biotechnol Adv 2013;31:482-8.

46. Manzoni P, Meyer M, Stolfi I, et al. Bovine lactoferrin supplementation for prevention of necrotizing enterocolitis in very-low-birth-weight neonates: a randomized clinical trial. Early Hum Dev 2014;90:S60-5.

47. Samanta M, Sarkar M, Ghosh P, et al. Prophylactic probiotics for prevention of necrotizing enterocolitis in very low birth weight newborns. 7 Trop Pediatr 2009;55:128-31. 